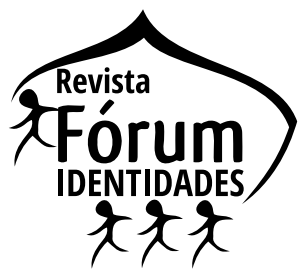

\title{
FORMAÇẪO CONTINUADA DE PROFESSORES DAS ESCOLAS DO CAMPO EM SERGIPE
}

\author{
Continued Formation of teachers \\ from rural schools in Sergipe.
}

\author{
Marilene Santos ${ }^{2}$ \\ Joelma Carvalho Vilar ${ }^{3}$
}

\begin{abstract}
Resumo: $\mathrm{O}$ artigo traz os resultados preliminares de uma pesquisa sobre formação continuada vinculada ao projeto Escola da Terra/Sergipe, desenvolvida no período 2018-2019, com profissionais da educação de 14 municípios sergipanos. Tem o objetivo de refletir sobre as contribuições da formação continuada para professores de escolas multisseriadas do campo em Sergipe. A investigação se apoia na abordagem teórica histórico-cultural e utiliza como instrumento de pesquisa os relatórios de campo de 14 profissionais envolvidos no projeto. Conclui-se que a experiência formativa em Sergipe promoveu mudanças qualitativas nas práticas docentes; na aprendizagem dos alunos e no envolvimento da comunidade com a escola, trazendo ainda a demonstração da viabilidade de se fazer a formação continuada de professores diretamente vinculada à realidade e à dinâmica educativa das escolas multisseriadas do Campo.
\end{abstract}

Palavras-chave: Formação Continuada. Escola Multisseriada. Educação do Campo.

\begin{abstract}
This article presents the preliminary results of a research on continuing education linked to the project Escola da Terra/Sergipe, developed in the period 2018-2019, with educational professionals from 14 municipalities in Sergipe. It aims to reflect on the contributions of continuing education for teachers in rural multi-grade schools in Sergipe. The investigation is based on the historical-cultural theoretical approach and uses as a research instrument the field reports of 14 professionals involved in the project. It is concluded that the formative experience in Sergipe promoted qualitative changes in teaching practices; in the students' learning and in the community's involvement with the school, also showing the feasibility of making the formation of teachers directly linked to the reality and to the educational dynamics of the multi-grade schools in the countryside.
\end{abstract}

Keywords: Continued formation. Multi-grade school. Rural Education.

\footnotetext{
${ }^{1}$ Artigo recebido em 15 de novembro de 2020 e aceito em 5 de fevereiro de 2021.

2 Doutora em Educação. Professora Adjunta do Departamento de Educação da Universidade Federal de Sergipe. É líder do grupo de pesquisa Educação e Movimentos Sociais - GPEMS. Membro do Grupo de Estudos e Pesquisa Identidades e Alteridades: diferenças e desigualdades na educação - GEPIADDE, Grupo de Pesquisa Clínica da Atividade e Trabalho Docente da UFS, e colaboradora do grupo de Estudos e Pesquisas em Avaliação e Currículo -GEPAC da UNIRIO. E-mail: mari.santos@uol.com.br. ORCID: https://orcid.org/0000-0002-7123-0415.

${ }^{3}$ Doutora em Educação. Professora Associada do Departamento de Educação da Universidade Federal de Sergipe. É pesquisadora do grupo de pesquisa Educação e Movimentos Sociais - GPEMS. E-mail: joelmavilar@hotmail.com. ORCID: https://orcid.org/0000-0002-2899-0785.
} 


\section{Introdução}

A educação escolar pleiteada pela população camponesa através de seus movimentos sociais do campo deve se constituir como um importante instrumento de fortalecimento da luta e da resistência na defesa do território camponês. Essa educação precisa superar a estrutura e a forma da escola moderna excludente e, para tanto, requer a participação de todos os sujeitos, desde a organização curricular até a gestão administrativa e pedagógica; necessita melhorar a qualidade social da formação escolar das crianças e dos jovens camponeses. As políticas educacionais aliadas à pesquisa se configuram como potenciais aliadas para refletir, analisar e contribuir na propositura de estratégias que garantam tais pleitos.

O direito à educação para a população camponesa, mesmo que já esteja garantido na legislação educacional, tem, na prática, pouco se efetivado na relação escola e campo. A escola continua com dificuldade de estabelecer vínculo com a vida camponesa. É uma escola que está no campo, mas com fortes marcas do urbano. É ainda difícil identificar nas escolas do campo características de uma educação planejada e organizada para atender às especificidades do meio rural (SANTOS, 2005). Ao nosso ver, a luta pelo direito a uma Escola do Campo de qualidade supera a ideia de que devemos adequar essa escola aos moldes da escola urbana e, ademais, ela representa a garantia de uma política de atendimento educacional às comunidades rurais a partir da identidade local e da diversidade sociocultural.

A propagação de iniciativas educacionais organizadas pelos movimentos sociais do campo se configurou como um espaço de demonstração de diferentes concepções educativas e de propostas pedagógicas, assim como de produção teórica sobre a Educação do Campo, que foram referência para a elaboração de políticas educacionais voltadas para as especificidades educativas do campo; a exemplo do Pronera (Programa Nacional de Educação na Reforma Agrária, do Programa Projovem Campo - Saberes da Terra, do Programa Educação nos Quilombos, do Programa Escola Ativa, e do Pronacampo (Escola da Terra voltada à formação continuada de professores atuantes no ensino multisseriado das escolas do campo.

Nesse artigo, cuja proposta é fazer uma leitura da incidência do Projeto Escola da Terra/Sergipe, trazemos dados de pesquisa desenvolvida no decorrer da implementação do Curso de Aperfeiçoamento para professores que trabalham com turmas multisseriadas e em escolas de comunidades quilombolas nos municípios sergipanos. Esse curso de180 horas, desenvolvido pela Universidade Federal de Sergipe, contou com a participação de 340 professores e técnicos de secretarias de educação de 14 municípios; e, do ponto de vista metodológico, com o intuito de promover a melhoria das condições de acesso, permanência e aprendizagem dos professores das escolas do campo, estruturou-se nos princí- 
pios e fundamentos da Pedagogia da Alternância, com seus respectivos Tempo Comunidade e Tempo Universidade.

A intencionalidade da pesquisa é refletir sobre as contribuições da formação continuada de professores de ensino multisseriado, representada pelo Curso de Aperfeiçoamento do projeto Escola da Terra/Sergipe, através da análise dos indicativos de mudança nas práticas dos professores; na aprendizagem dos alunos; no envolvimento da comunidade com a escola e na própria formação continuada de professores.

Os dados analisados foram coletados através dos relatórios de campo, desenvolvidos no Tempo Comunidade, de 14 tutores. Nossa análise se centra nos indicativos do trabalho pedagógico dos professores resultantes do processo formativo do Curso de Aperfeiçoamento do Escola da Terra/Sergipe. A pesquisa está situada no quadro teórico histórico-cultural e encontra as marcas dos processos de reflexão-ação-reflexão docente, e da sua cultura profissional, nas narrativas presentes nos relatórios de campo. Desse modo, o relatório de campo foi instrumento de pesquisa basilar para a obtenção e a produção de informações. Por certo, o uso desse instrumento metodológico foi o que nos aproximou da realidade docente do campo e auxiliou nas reflexões e tomadas de decisões pedagógicas durante os módulos do Tempo Universidade do Curso de Aperfeiçoamento.

Tais relatórios revelaram as inquietações, as dúvidas, os interesses e os desafios próprios dos docentes, além de permitirem o acompanhamento de todo o processo de formação docente pela equipe de coordenação do curso. Os registros, do ponto de vista metodológico, foram regidos pelos princípios da frequência, da cronologia e da periodicidade das anotações (GÓMEZ; FLORES; JIMÉNEZ, 1999). Nas análises, obedecendo aos critérios de veracidade em pesquisa qualitativa (GUBA, 1981), foram considerados os seguintes registros: os planos de intervenção, as ações docentes e as reflexões sobre as suas ações; o que permitiu vivenciar, desde uma vivência teórico-metodológica, o ciclo do professor reflexivo (IMBERNÓN, 2011).

$\mathrm{O}$ artigo está estruturado em duas partes inter-relacionadas. A primeira, intitulada Trilhas e percursos na formação continuada de professores, trata, desde uma abordagem mais ampla, das questões relativas à formação continuada de professores do Campo e das políticas públicas educacionais que asseguram o direito a essa formação; para tanto, apresenta o programa Escola da Terra como política educacional propositiva no enfrentamento do déficit de formação de professores no Campo.

A segunda parte, Trilhas e percursos da pesquisa: sujeitos, metodologias, resultados, apresenta aspectos metodológicos e os resultados da pesquisa, tratando, a partir de um viés mais descritivo e interpretativo do campo no 
qual a pesquisa foi realizada, especificamente das experiências formativas vivenciadas no Curso de Aperfeiçoamento Escola da Terra entre 2018-2019. Nesse momento, mediante os apontamentos dos relatórios de campo, os professores das escolas multisseriadas do campo em Sergipe ganham protagonismo.

\section{Trilhas e percursos na formação continuada de professores}

Qualquer processo de organização e funcionamento da educação escolar não pode desconsiderar os profissionais da educação como sujeitos fundamentais, portanto, nessa pesquisa, contrariando a perspectiva hegemônica das políticas de formação docente, referenciamo-nos por outra concepção de formação que não adere aos propósitos das políticas neoliberais de responsabilização e individualização do docente sobre o êxito ou fracasso do aluno sem considerar as condições socioeconômicas e culturais que envolvem os processos de aprendizagem (FREITAS, 2007).

Compreendemos que o processo de formação docente se estabelece como uma dinâmica essencialmente relacional entre um sujeito (o professor) e o saber (os saberes considerados relevantes à sua imersão no processo pedagógico), imerso reflexivamente, tal como sugere Pombo (2011), em pelo menos três dimensões: a educativa, questionando as grandes finalidades da educação; a política, discutindo o significado e as funções da instituição escolar; e a epistemológica, exercitando permanentemente a autocrítica em relação ao próprio saber. Para esta autora, o elemento da reflexividade na formação de professores é componente fundamental e deve se constituir em três níveis:

O de uma reflexão educativa que interrogue e tematize as grandes finalidades da educação, que deslinde e dê conta do emaranhado de problemas e antinomias que se colocam a quem queira pensar seriamente as questões educativas; o de uma reflexão institucional que interrogue o significado e funções da instituição escolar; o de uma reflexão epistemológica e interdisciplinar que suscite a consciência crítica do professor relativamente ao seu próprio saber e lhe permita equacioná-lo na complexa situação atual de saberes (Ibid., p. 23).

É nesse exercício que se funda a prática docente crítica, que envolve um movimento dialético entre o fazer e o pensar sobre o fazer, tecendo, dessa forma, o que Freire (2001) denomina de "Formação Permanente", cujo momento fundamental é o da reflexão crítica sobre a prática. Nessa relação com o saber, o sujeito em formação deve considerar e entender:

A força que o território, a terra, o lugar tem na formação social, política, cultural, identitária dos povos do campo. Sem as matrizes que se formam sem entender a terra, o território e o lugar como 
matrizes formadoras, não seremos capazes de tornar a escola um lugar de formação. Sem a articulação entre o espaço da escola e os outros espaços, lugares, territórios onde se produzem, será difícil sermos mestres de um projeto educativo. A compreensão da especificidade desses vínculos entre território, terra, lugar, escola é um dos componentes da especificidade da formação de educadoras e educadores do campo (ARROYO, 2007, p. 163).

A formação de professores que contribua para uma escola nos moldes apontados por Arroyo (2007) não tem se efetivado na formação inicial; ao mesmo tempo, as oportunidades de se garantir formação continuada para os professores que atuam na educação do campo têm sido insuficientes, especialmente para os que trabalham com educação infantil e com os anos iniciais do ensino fundamental, visto que nos últimos vinte anos apenas dois programas voltados ao ensino multisseriado foram implementados em todo o território nacional: o Programa Escola Ativa - que, no auge de cobertura, atingiu aproximadamente 90\% do território (KNIJNIK; WANDERER, 2013) - e o Projeto Escola da Terra - que, até o momento (há ainda indefinição em relação a continuidade do projeto pelo Ministério da Educação), somente atende a 28\% da demanda por formação continuada (SOUZA NETO, 2018). Entretanto, a formação continuada para professores é garantida como direito na Lei de Diretrizes e Bases da Educação (LDB), e reconhecida como necessária para elevar a qualidade da educação brasileira no Plano Nacional de Educação (PNE 2014-2024).

A formação continuada, como direito, contempla três aspectos conceituais na LDB: capacitação em serviço (Art. 61, Inciso I); aperfeiçoamento profissional continuado (Art. 67, Inciso II); e treinamento em serviço (Art. 87). A despeito do caráter instrumental da formação continuada garantida na LDB, especificamente ao conceituar tal formação como "capacitação, treinamento" - evidenciando uma formação voltada para a adaptação e ou a padronização de um sujeito (professor/a) considerado incapaz, ineficiente -, a ideia do aperfeiçoamento continuado abre espaço para o que defendemos no âmbito da formação continuada como elemento de produção de autonomia do sujeito "inacabado" (Freire, 2001), que reflete sobre sua prática não para moldá-la, mas para transformá-la. "Na formação permanente dos professores, o momento fundamental é o da reflexão crítica sobre a prática. É pensando criticamente a prática de hoje ou de ontem que se pode melhorar a próxima prática" (Ibid., p. 43-44).

Na mesma direção, Imbernón (2011, p. 41) afirma que: “o processo de formação deve dotar os professores de conhecimentos, habilidades e atitudes para desenvolver profissionais reflexivos ou investigadores". Para este autor, a formação continuada/permanente precisa garantir aos professores: elementos relativos aos processos; conhecimentos de metodologias que visem a participa- 
ção, a observação, as estratégias, a comunicação, a tomada de decisões, possibilitando, assim, que atuem de forma autônoma em contextos e realidades educativas carentes de intervenção pedagógica.

Seguindo a compreensão freiriana no que diz respeito à formação, Ferreira (2010, p. 5) afirma que:

A formação corresponde a uma transformação pessoal, interior e ligada à experiência de cada sujeito que se permite - e se possibilita - mudar pelo conhecimento construído neste processo. Assim, é o sujeito que se forma. Dado o nosso permanente inacabamento, estamos destinados a nos formarmos. Porém, embora a formação corresponda a um acontecimento de ordem individual, ninguém se forma sozinho. Formamo-nos na relação e interação com o(s) outro(s).

Enfatizamos a necessidade de formação continuada como elemento da inconclusão humana, fator que nos possibilita estar em permanente processo de formação; nesse sentido, Freire (1997, p. 20) afirma que:

A educação é permanente não porque certa linha ideológica ou certa posição política ou certo interesse econômico o exijam. A educação é permanente na razão, de um lado, da finitude do ser humano, de outro, da consciência que ele tem de finitude. Mas ainda, pelo fato de, ao longo da história, ter incorporado à sua natureza não apenas saber que vivia, mas saber que sabia e, assim, saber que podia saber mais. A educação e a formação permanente se fundam aí.

Compreendendo a formação continuada como um processo que ocorre durante toda a trajetória profissional dos professores e que está garantida como direito na legislação em vigor, debruçamo-nos sobre as políticas que garantem tal direito. A necessidade de tais políticas pode ser evidenciada quando observamos o que o PNE 2014-2024 estabelece como metas e estratégias no âmbito da formação continuada, visto que é nele que se delibera sobre as prioridades de investimentos em educação para cada década.

Em todo o PNE, somente a meta 16 foca a formação continuada dos professores:

Formar, em nível de pós-graduação, 50\% dos professores da educação básica, até o último ano de vigência deste PNE, e garantir a todos(as) os(as) profissionais da educação básica formação continuada em sua área de atuação, considerando as necessidades, demandas e contextualizações dos sistemas de ensino (BRASIL, 2015, p. 275).

A meta dezesseis prevê que todos/as tenham formação continuada, entretanto, nada estabelece formas e condições para garantir tal formação. O percentual de garantia desse direito, quando da elaboração do PNE, era de 30,6\% para 
participação em curso com carga horária mínima de 80 horas. Conforme dados do INEP, obter informações sobre a formação continuada era um desafio a ser enfrentado. Os cursos realizados nas áreas de educação indígena, educação do campo, educação ambiental, educação em direitos humanos, gênero e diversidade sexual e direitos da criança e do adolescente não alcançaram 1,0\%. (BRASIL, 2015, p. 284).

$\mathrm{Na}$ área da educação para a população camponesa, os dados demonstram uma expressiva ausência de atendimento, visto que esses professores não chegam a representar sequer $1 \%$ dos participantes de algum curso, num universo de 351.246 professores que, em 2013, trabalhavam em escolas do campo (SOUZA NETO, 2018, p. 266). Buscando o enfrentamento desse déficit, o Ministério da Educação instituiu, através da portaria no 579 de 2 de julho de 2013, o Projeto (Ação) Escola da Terra. O atendimento do Escola da Terra se dá a partir da adesão das universidades; portanto, a cobertura de todas as cinco regiões do país só se completou na quarta edição do projeto, mesmo não estando presente em todos os Estados, conforme se vê no quadro a seguir.

Quadro 1: Dados de cobertura do Escola da Terra por Estado e Região

\begin{tabular}{|c|c|c|}
\hline ANO & REGIÃO & ESTADO \\
\hline \multirow[t]{4}{*}{2014} & Norte & Amapá, Pará \\
\hline & Nordeste & Bahia, Maranhão, Pernambuco, Ceará \\
\hline & Sul & Rio Grande do Sul, Santa Catarina \\
\hline & Sudeste & Espírito Santo, Minas Gerais \\
\hline \multirow[t]{4}{*}{2015} & Norte & Amapá, Pará \\
\hline & Nordeste & Bahia, Maranhão, Pernambuco, Ceará, Alagoas, Rio Grande do Norte \\
\hline & Sul & Rio Grande do Sul, Santa Catarina, Paraná \\
\hline & Sudeste & Espírito Santo, Minas Gerais \\
\hline 2016 & \multicolumn{2}{|c|}{ Não houve ingresso. Foram mantidos os Estados de 2015.} \\
\hline \multirow[t]{5}{*}{2017} & Norte & Amazonas, Pará, Amapá, Tocantins \\
\hline & Nordeste & $\begin{array}{l}\text { Bahia, Maranhão, Pernambuco, Ceará, Alagoas, Rio Grande do Norte, } \\
\text { Sergipe, Piauí, Paraíba }\end{array}$ \\
\hline & Sul & Rio Grande do Sul, Santa Catarina, Paraná \\
\hline & Sudeste & Espírito Santo, Minas Gerais, São Paulo \\
\hline & Centro-Oeste & Distrito Federal, Mato Grosso, Goiás \\
\hline
\end{tabular}

Fonte: Sistema Integrado de Monitoramento Execução e Controle do MEC (SIMEC). Elaboração das autoras.

A primeira edição do projeto, em 2014, teve adesão de dez Estados, e em 2017, com 22 adesões, já havia alcançado 100\% deles. O planejamento do MEC para 2018 (que não se concretizou por conta de cortes orçamentários) já incluía a 
adesão dos demais Estados (Acre, Rondônia, Roraima, Rio de Janeiro e Mato Grosso do Sul), fator que garantiria a cobertura do projeto em todo o território nacional.

Em análise dos resultados do projeto no decorrer das três edições, Souza Neto (2018, p. 273) afirma que:

O projeto tem alcançado bons resultados o que se traduz na credibilidade perante os beneficiários da ação (Professores do Campo) e também nas reações entes e agentes envolvidos fora e dentro do MEC. Com apenas três anos de existência, ainda que pesem os sucessivos cortes de recursos financeiros que retraiu a oferta, sobretudo 2015-2016, o projeto superou as metas estabelecidas, considerando a relação vaga oferta x recurso disponibilizado x metas cumpridas/atingidas.

O que trazemos na seção seguinte são os resultados do Escola da Terra em Sergipe, cuja participação na última edição de um projeto piloto, um curso de aperfeiçoamento de 180 horas, contou com os registros dos tutores nos relatórios de campo.

\section{Trilhas e percursos da pesquisa: sujeitos, metodologias, resultados}

Os dados aqui analisados foram selecionados dos relatórios de campo dos tutores através dos seguintes aspectos metodológicos: no primeiro momento, realizamos a leitura dos relatórios mensais dos tutores para identificar possíveis evidências de intervenção e reflexão pedagógica nas práticas dos professores participantes do projeto. Num segundo momento, realizamos a leitura dos relatórios finais, com o mesmo objetivo do primeiro momento. Os recortes de escrita dos relatórios que utilizamos neste artigo fazem parte do conteúdo dos relatórios finais, por estes retratarem de forma avaliativa mais ampla os impactos do projeto nas práticas dos professores.

Participaram do projeto como tutores 29 técnicos/as das secretarias de educação dos 14 municípios sergipanos comtemplados. O quantitativo de tutores/as por município era definido a partir do número de professores/as participantes numa proporção estabelecida na resolução n. 38 de outubro de 2013 do MEC, conforme redação do art. $4^{\circ}$ parágrafo IV, letra a: "promover seleção pública para escolher, obrigatoriamente entre os professores de sua rede, aqueles que assumirão a função de tutores, na proporção de um tutor para cada 7 a 15 professores das escolas do campo e escolas quilombolas" (BRASIL, 2013, p. 4). Importante destacar que os relatórios de campo dos/as tutores/as eram elaborados por município, assim, cada relatório tinha a autoria de mais de um/a tutor/a. Nesse sentido, o material de análise aqui apresentado foi constituído de 14 relatórios, e, quanto à nossa pesquisa, de abordagem qualitativa, podemos di- 
zer que "se embasa na construção coletiva dos sujeitos e leva em conta as mediações socioculturais a partir das quais os mesmos se constituem” (BAPTAGLIN; ROSSETTO; BOLZAN, 2014, p. 417).

$\mathrm{Na}$ pesquisa qualitativa, o interesse investigativo é direcionado muito mais para a compreensão e interpretação dos diferentes contextos experenciados pelos sujeitos da investigação, do que para meros resultados. Dessa forma, nossas questões para a pesquisa:

\begin{abstract}
Não são estabelecidas a partir da operacionalização de variáveis, mas se orientam para a compreensão dos fenômenos em toda a sua complexidade e nem seu acontecer histórico. Isto é, não se cria artificialmente uma situação para ser pesquisada, mas se vai ao encontro da situação no seu acontecer, no seu processo de desenvolvimento (FREITAS, 2002, p. 27).
\end{abstract}

Isso nos conduz a um permanente processo de aprendizagem, que abrange tanto pesquisador/a como pesquisados/as:

O pesquisador, durante o processo de pesquisa, é alguém que está em processo de aprendizagem, de transformações. Ele se ressignifica no campo. $\mathrm{O}$ mesmo acontece com o pesquisado que, não sendo um mero objeto, também tem oportunidade de refletir, aprender e ressignificar-se no processo de pesquisa (Ibid., p. 26).

Foi realizada a leitura dos 14 relatórios de campo, nos quais identificamos questões recorrentes que, por fim, constituíram-se em quatro eixos de análise, todos relacionados às observações feitas pelos/as tutores/as sobre o processo de formação continuada através do projeto Escola da Terra nos seus municípios: 1) mudanças nas práticas dos professores; 2) avanço na aprendizagem dos alunos; 3) importância da formação continuada; e 4) envolvimento da comunidade com as atividades da escola. Para orientar nossa análise e preservar as identidades dos professores, numeramos os municípios de um a quatorze $(1-14)$ e as letras T e M (tutor; município).

Compreendendo a formação continuada como elemento transformador da prática docente, capaz de produzir reflexão, renovação, criação e intervenção, trazemos alguns recortes de escrita dos relatórios dos/as tutores/as que evidenciam tal compreensão:

No decorrer do programa foi possível perceber a importância da Formação Continuada, pois foi nesta que a maioria dos professores aprenderam a elaborar a sequência didática para trabalhar com turmas multisseriadas, construir um projeto de Intervenção partindo de um diagnóstico aplicado (TM8). 
De acordo com os relatos acima, os processos de formação continuada desencadeiam e/ou provocam nos professores movimentos pedagógicos diferentes dos habituais: uma nova forma de elaborar o planejamento, novos projetos didáticos, novas aprendizagens, outros conhecimentos. A formação continuada funciona, como destaca Falsarela (2004, p. 50):

\footnotetext{
Entendendo a formação continuada como proposta intencional e planejada, que visa a mudança do educador através de um processo reflexivo, crítico e criativo conclui-se que deva motivar o professor a ser ativo agente na pesquisa de sua própria prática pedagógica, produzindo conhecimento e intervindo na realidade.
}

Na mesma direção, Imbernón (2010, p. 75) reforma a importância dos conhecimentos adquiridos a partir de processos formativos continuados, no caso de se constituírem em ferramentas para tornar os professores reflexivos, críticos, criativos:

O conhecimento profissional consolidado mediante a formação permanente apoia-se tanto na aquisição de conhecimentos teóricos e de competências de processamento da informação, análise e reflexão crítica em, sobre e durante a ação, o diagnóstico, a decisão racional, a avaliação de processos e a reformulação de projetos.

De nossa parte, afirmamos que a formação continuada altera as práticas pedagógicas dos professores; por isso é tão importe que os sistemas educacionais garantam políticas de formação continuada aos professores, especialmente àqueles do ensino multisseriado, que historicamente têm sido relegados à condição de educação de segunda categoria. Os recortes a seguir demonstram quão significativas são as mudanças produzidas nas práticas dos professores a partir de um curso de aperfeiçoamento.

\footnotetext{
No decorrer da formação, houve mudanças em todas as unidades escolares do campo, como, por exemplo, o envolvimento dos alunos nos temas que foram abordados em sala de aula, os quais tiveram como contexto e parâmetro de comparação as realidades vividas por estudantes e seus familiares. Também a equipe gestora dessas escolas se envolveu na comunidade para resgatar a história socioeconômica de seu respectivo povoado (TM2).
}

Os alunos das escolas com turmas multisseriadas são apontados (por professores, gestores, entre outros) como estudantes com baixo desempenho escolar. Muitas escolas do campo, as multisseriadas especialmente, sequer são incluídas na avaliação nacional que mede o Índice de Desenvolvimento da Educação Básica (IDB). A questão é tratada como se a responsabilidade pelo baixo desem- 
penho fosse das próprias escolas e de seus estudantes, ao invés de ser considerada como uma questão de política educacional dos diversos sistemas, os quais, sem nenhum critério ou orientação pedagógica, têm utilizado o ensino multisseriado apenas como ajuntamento de anos escolares dentro de uma única sala de aula.

Não afirmamos que a formação dos professores seja a solução para um problema de tal complexidade, entretanto, sabemos até que ponto práticas docentes críticas, reflexivas, com domínio do conhecimento pedagógico específico podem contribuir de forma significativa para a reversão dos baixos índices de aproveitamento escolar dos estudantes. Os relatos a seguir podem ser pistas nesse sentido:

Com as atividades realizadas, baseadas na orientação do curso, percebeu-se que os alunos ficaram mais interessados e que tiveram um avanço no processo de aprendizagem. Pudemos perceber que, com o conjunto de conhecimentos adquiridos e as práticas desenvolvidas, obtivemos resultados satisfatórios no que diz respeito ao processo ensino aprendizagem de nossos alunos (TM3).

Um curso de formação continuada pode, a princípio, parecer insuficiente para produzir transformações de tão elevado nível, entretanto, apontam para a riqueza e o poder que tais transformações exercem nesse complexo universo da educação escolar. Para Imbernón (2010, p. 85):

A formação centrada na escola envolve estratégias empregadas conjuntamente pelos formadores e pelos professores para dirigir os programas de formação, de modo que respondam às necessidades definidas da escola e, assim, elevar a qualidade do ensino e da aprendizagem em sala de aula e nas escolas.

O projeto Escola da Terra/Sergipe tinha como campo de estudo na formação dos professores a escola e a comunidade escolar, por isso a importância de se ter a Pedagogia da Alternância como eixo metodológico principal, visto que essa pedagogia, de acordo com Hage e Pena (2018, p. 122):

Busca mudanças na forma tradicional de se socializar e produzir conhecimento científico: ao favorecer um vínculo permanente entre o conhecimento que a ciência produz e as questões da vida no campo, propõe que os fenômenos que envolvem a problemática do campo sejam estudados em toda a sua complexidade, tal como existem na realidade, por meio de uma abordagem que dê conta de compreender totalidades, nas suas contradições, no seu movimento histórico.

Outro aspecto da potencialidade do projeto Escola da Terra/Sergipe que podemos ressaltar está relacionado ao princípio pedagógico da Educação do Campo, "da valorização dos diferentes saberes no processo educativo" (BRA- 
SIL/MEC, 2005, p. 37). Nesse princípio, a escola deve considerar e levar em conta os conhecimentos "que os pais, os/as alunos/ as, as comunidades possuem, e resgatá-los dentro da sala de aula num diálogo permanente com os saberes produzidos nas diferentes áreas de conhecimento" (Ibid., p. 37).

É possível ainda notar a interação aluno-escola-famíliacomunidade, a qual fomentou o desejo de alunos e pais pedirem para permanecer na escola porque não querem estudar na zona urbana. Os pais começaram a participar mais das ações das escolas; depois das palestras, os alunos têm prazer em descobrir as suas origens e construir sua história (TM 5).

Os relatos acima descritos demonstram que o projeto Escola da Terra/ Sergipe foi responsável por movimentos diferentes em algumas comunidades camponesas no Estado de Sergipe, que se sentiram atraídas pela escola. Os projetos propostos pelos professores geraram a "valorização dos fazeres e saberes dos homens e mulheres do campo" (TM 2); desencadearam "o desejo de alunos e pais para permanecer na escola”. Isso evidencia a importância de se criar iniciativas democrático-participativas que estimulem as interações sociais no sentido de produzir uma escola que dê passos na direção de criar e fortalecer laços com a comunidade. Uma escola que se constitui para além do simples ensinar o conteúdo. Uma escola que se importa com a comunidade e que também seja importante para ela. E iniciativas dessa ordem passam a ser viáveis a partir de processos permanentes de formação continuada.

\section{Considerações finais}

Neste artigo, evidenciamos, a partir de recortes dos relatórios de campo dos tutores, que a formação continuada dos professores é um fator extremamente significativo no processo educacional para produzir transformações na prática docente. Identificamos que projetos como esse podem se constituir em potenciais veículos para a alteração na relação escola, família e comunidade, principalmente a partir da implementação de projetos articulados com a vida dos estudantes e demais pessoas da comunidade externa a escola.

O desenvolvimento do projeto Escola da Terra/Sergipe oportunizou relevantes processos de troca e compartilhamento de conhecimentos entre os professores cursistas, os professores formadores e os estudantes de graduação, confirmando o que dizia Freire: "quem ensina aprende ao ensinar e quem aprende ensina ao aprender (FREIRE, 2001, p. 25).

Nesse sentido, evidencia-se a necessidade de políticas permanentes de formação continuada, especialmente para professores da educação do campo 
que, já na formação inicial, são prejudicados por currículos que não incluem conhecimentos referentes aos desafios do território camponês e sua relação política e pedagógica com as escolas que nele estão situadas. A implementação de projetos desse tipo contribui para promover a interação entre escola e comunidade, suscitar a reflexão sobre os seus problemas, identificar as suas potencialidades e construir/consolidar a sua história, sua/s identidade/s por meio de processos educativos contextualizados, humanizados e emancipatórios.

Diante das evidências apontadas através das análises da investigação, é possível compreender que a experiência formativa do Curso de Aperfeiçoamento do projeto Escola da Terra/Sergipe promoveu mudanças qualitativas nas práticas docentes; na aprendizagem dos alunos e no envolvimento da comunidade com a escola. Além disso, demonstrou a viabilidade concreta de se fazer a formação continuada de professores diretamente vinculada à realidade e à dinâmica educativa das escolas multisseriadas do campo. Afirma-se, assim, que o "lugar" e o "tempo" privilegiados para se realizar uma formação continuada comprometida com a mudança qualitativa habita no movimento dialógico da reflexão-ação-reflexão com as escolas do campo.

\section{Referências}

ARROYO, Miguel Gonzalez. Políticas de formação de educadores(as) do campo. Caderno Cedes, Campinas, v. 27, n. 72, p. 157-176, mai./ago. 2007.

BAPTAGLIN, Leila Adriana; ROSSETTO, Gislaine Aparecida Rodrigues da Silva; BOLZAN, Doris Pires Vargas. Professores em formação continuada: narrativas da atividade docente de estudo e a da aprendizagem da docência. Educação: Santa Maria, v. 39, n. 2, p. 415-426, mai./ago. 2014.

BRASIL. Instituto Nacional de Estudos e Pesquisas Educacionais Anísio Teixeira. Plano Nacional de Educação PNE 2014-2024: Linha de Base. Brasillia, DF: Inep, 2015.

BRASIL. Resolução $\mathbf{N}^{\mathbf{o}} 38$ de 08 de outubro de 2013: Estabelece orientações e procedimentos para o pagamento de bolsas de estudo e pesquisa no âmbito da Escola da Terra escola da Terra. Brasília: MEC/FNDE, 2013.

BRASIL. MEC. Referências para uma política nacional de educação do campo: caderno de subsídios. Grupo Permanente de Trabalho de Educação do Campo. Coordenado por Marise Nogueira Ramos, Telma Maria Moreira e Clarice Aparecida dos Santos. 2 ed. Brasília: MEC/SECAD, 2005.

FALSARELLA, Ana Maria. Formação continuada e prática de sala de aula: os efeitos da transformação continuada na atuação do professor. Campinas (SP): Autores Associados, 2004. 
FERREIRA, Claúdia Roberta. Diálogos na/com a formação de professores. In: Fala Outra Escola, v. 5, 2010, Campinas. Anais [...]. Campinas: Gepec, 2010, p. 1-15.

FREITAS, Helena Costa Lopes de. A (nova) política de formação de professores: a prioridade postergada. Educação \& Sociedade, Campinas, v. 24, n. 100, p.1203-1230, out. 2007. (Número Especial).

FREITAS, Maria Teresa de Assunção. A abordagem sócio histórica como orientadora da pesquisa qualitativa. Cadernos de Pesquisa, São Paulo, n. 116, p. 20-39, jul. 2002.

FREIRE, Paulo. Pedagogia da Autonomia. Rio de Janeiro: Paz e Terra, 2001.

Freire, Paulo. Política e educação. São Paulo: Cortez, 1997.

GÓMEZ, Gregorio Rodríguez; FLORES, Javier Gil.; JIMÉNEZ, Eduardo García. Metodología de la investigación cualitativa. 2 ed. Málaga: Aljibe, 1999.

GUBA, Egon G. Criterios de credibilidad en la investigación naturalista. In:SACRISTÁN José Gimeno; PÉREZ Gómez, Angel. La enseñanza: su teoría y su práctica. Madrid: Akal, 1981.

HAGE, Salomão Antônio Mufarrej; Pena, Selma Costa. Programa Escola da Terra, das Águas e da Floresta: experiência de formação de educadores contextualizada e afirmativa da diversidade sociocultural e territorial da Amazônia paraense. In: HAJE, Salomão Antônio Mufarrej et al. (org.). Programa Escola da Terra: cartografia da diversidade e complexidade de sua execução no Brasil. Curitiba: Editora CRV, 2018.

IMBERNÓN, Francisco. Formação continuada de professores. Porto Alegre: Artmed, 2010.

KNIJNIK, Gelsa; WANDERER, Fernanda. Programa Escola Ativa, escolas multisseriadas do campo e educação matemática. Educ. Pesquisa. São Paulo, v. 39 n.1, p. 211-225, jan./mar. 2013.

POMBO, Olga. Para um modelo reflexivo de formação de professores. In: SANTOS, Carlos Alberto dos; QUADROS, Aline Ferreira de (org.). Utopia em busca de possibilidade: abordagens interdisciplinares no ensino das ciências da natureza. Foz do Iguaçu: UNILA, 2011.

SANTOS, Marilene. Práticas Sociais da Produção e Unidades de Medida em Assentamentos do Nordeste Sergipano: um estudo Etnomatemático. Orientadora: Gelsa Knijkik. 2005. 126 páginas. Dissertação (Mestrado em Educação) - Programa de Pós-graduação em Educação, Universidade do Vale do Rio dos Sinos (UNISINOS), São Leopoldo, 2005.

SOUZA NETO, Xavier Carvalho de. Formação de Professores e Valorização do Magistério: contribuições da ação escola da terra na formação continuada de professores para escolas do campo. In: HAJE, Salomão A. M et al. (org.). Programa Escola da Terra: cartografia da diversidade e complexidade de sua execução no Brasil. Curitiba: Editora CRV, 2018. 